\title{
7 In lieu of a Conclusion
}

\subsection{Original ending}

I have thought long and hard about how to finish up this project. How does one write an ending to this investigation that in no way concludes? Originally, I decided to end with part of an interview that has had a lasting impact on me precisely because it invokes the myriad nuances and ambivalences activated by improv's anti-Blackness. This decision was counterintuitive for me; in many ways, the content of the excerpt opposes the general argument of my project and undercuts its logic from the specific viewpoint of a Black-racialized performer. It articulates an optimism of the will that I would like to leave to the improvisers themselves. In this excerpt, Warren Phynix Johnson, who claims to enter every scene as a white character because it is (perceived as) a "neutral character," adopts a position beyond morality that can be related to Afro-pessimist axioms. However, he simultaneously elaborates an argument for an aesthetic transcendence of the racial matrix that enables improv's performative specificities. This move happens in the register of a politics of hope I have repeatedly dismissed. However, it is not up to me to judge the way that Black-racialized improvisers deal with and talk about racism in improv - especially not as a white man from a different continent who has spent a grand total of 13 days in Chicago. One final look, then, at a conversation that took place in a Mexican lunch bar among four improvisers - one Black, one white, one Asian American, and myself - grounded in years of professional experience, and as rich in references to Martin Luther King as Leonard Nimoy.

Johnson: As a white person on a stage, you can do anything. You can sexually harass people. You can be racist. You can do anything as a white person.

Questioner: But that's not a good thing.

Johnson: It doesn't matter if it's good or not. It matters that you can do it. So what? Me being a charismatic person, period. I can get away with a lot of shit. I do get away with a lot of shit. Granted, race-wise, I get it, you can do this, you can do that. But also as a charismatic person, you can do this and do that. As an attractive person, you can do this or do that. As a person who likes Star Trek! There are so many things you can get away with. If there's a thing that you're into, and you work that thing, you can get away with it. I feel like society is so hindered by race. Fuck all race, man! It's not about race. It's about what you can do as a person. Now, if you're stuck on race - that's fine, and that's cute. But say you're coming to the guy who is stuck on race as a guy who likes Star Trek -

Schleelein: I love this analogy.

Johnson: Thank you very much! Granted, there is a guy who is racist, but this fucking Puerto Rican loves Leonard Nimoy. He loves DeForest Kelly like he is into this -

Schleelein: James Doohan?

2 OpenAccess. (C) 2022 Michel Büch, published by De Gruyter. (cc) BY-NC-ND This work is licensed under the Creative Commons Attribution 4.0 International License. https://doi.org/10.1515/9783110752748-008 
Johnson: Everybody likes Scotty, of course. But they are into their thing. And if you work the thing that you're into, it doesn't matter what color you are. All that matters is what you care about. The content of your character. What are you into? Sometimes when it's like "Ohhh, the black thing..." or "Ohhh minority, so-and-so-and-so-and-so." Fuck that shit! I'm here because I am into improv.

Schleelein: I have a question now. Do you think that any of the actions that you have ever done, as a quote-unquote "minority performer -"

Johnson: Get it out, you little -

Schleelein: Do you think that any of the things you have ever done on stage has changed somebody's mind about not liking black people? Do you think that you have changed a racist $\mathrm{mi}-$

Johnson: Absolutely.

Schleelein: Really?

Johnson: Absolutely. Doing a show in - and I'm not saying these people are racist - in Okojobi, Iowa. I toured for about two years with Second City, and you go literally everywhere. And you go to these small towns. I had a guy tell me I was Dan Aykroyd. A white guy. Older, chunky, heavy-set gentlemen. He goes, "You're Dan Aykroyd! They cast a certain way, and you're the Dan Aykroyd guy!" You understand? It's like a style of comedy, a brand of comedy.

Arashiba: Maybe at that time you were.

Schleelein: Blackroyd. Black Dan Aykroyd. But did you change a racist mind?

Johnson: Yeah, totally! This guy is totally not going to fuck with black people. Listen, to him say to me, "You're Dan Aykroyd," made me feel good. Because this guy is a fucking racist for sure, but he's like, "I enjoy the show, and I also understand how they cast and how they work.” So, if they're casting for Dan Aykroyd, if they're casting for Bill Murray, if they're casting for - who the fuck is Better Call Saul?

Schleelein: Bob Odenkirk.

Johnson: Right. If you want to put a person in a category, what matters isn't race but style of comedy, brand of comedy. So, he was just like, "Yo - you're the Dan Aykroyd of the group." Comedy transcends race. Even when people are doing horrible, racist bits, you're still transcending race because we're laughing at it.

\subsection{Reality updates}

I have been working on this project for eight years, with long pauses due to personal circumstances. In those eight years, the anti-Blackness of US sociability has manifested publicly in many ways: the Charleston church shooting, the election of Donald Trump as president, the Charlesville attack, the El Paso shooting, the killings of numerous unarmed Black people by police officers, and more. In response, the Black Lives Matter movement has modified how the media reports on anti-Blackness and racism, and has inspired activism of many kinds. Within parts of the white improv community, a parallel sense of unease has developed. When I approached the improvisers I had interviewed to request permission to 
use the material, quite a few told me that times had changed and they would rather not be part of the project. In contrast, in my immediate improv environment, I have been able to talk about improv's fundamental anti-Blackness without being frowned on or sneered at. Yet nothing changed at the institutional level until very recently. What might have been a communal groundswell came to the fore shortly after the murder of George Floyd on 25 May 2020. Following allegations of institutional racism by Dewayne Perkins and Aasia Bullock, among others, Second City's long-time CEO Andrew Alexander resigned in June 2020. An article on vulture.com quotes them both:

On May 31, Second City tweeted a pro-Black Lives Matter in support of this week's ongoing protests against police brutality, a sentiment former black performers like comedian Dewayne Perkins responded to with some surprise, considering their own experiences at the theater.

"You remember when the black actors wanted to put on a Black Lives Matter Benefit show and you said only if we gave half of the proceeds to the Chicago PD, because I will never forget. Remember when you would make black people audition for job you simply just gave to white people?," the Brooklyn Nine-Nine writer tweeted in a threat Thursday. "Remember when you sent a bunch of your black actors to speech therapy because you said white people didn't understand us? Remember when you told me to my face I wasn't getting hired for main stage because I wasn't 'nice' enough and kept speaking out?"

Other performers of color described similar experiences on Twitter, including Space Force writer Aasia LaShay Bullock, who tweeted about the theater's alleged failure to address her by a white actor, pressuring her to perform alongside him until she was forced to quit. (Kiefer)

In a long public statement from 5 June 2020, Alexander considers the maintenance of institutional racism at Second City "one of the great failures of my life," while asserting that on stage "we have always been on the right side of the issue, and of that, I am very proud." In the letter, he also announces that the "next person to fill the Executive Producer position will be a member of the BIPOC [Black, Indigenous, and People of Color] community," a commitment that he is again "proud to make." A day after his resignation, Anthony LeBlanc was announced as interim executive until a long-term executive would be found. On 8 June, the following open letter by current and former Black Second City performers was disseminated online:

After a meeting with several Black alumni and current Second City employees, we have come to the conclusion that the erasure, racial discrimination, manipulation, pay inequity, tokenism, monetization of Black culture, and trauma-enducing experiences of Black artists at The Second City will no longer be tolerated. We cannot and will not let this abuse continue. As the artists whose names, images, and written material you still profit off of, we demand change. 
After careful review of the history of Black artists at The Second City, we call for the following:

- A thorough investigation and removal of teachers, producers, directors, and other adminstrative staff guilty of microaggressions, racial transgressions, cultural appropriation, mental and verbal abuse against the Black artists who built your stages.

- A thorough investigation organization-wide and immediate removal of anyone guilty of sexual misconduct and sexual assault.

- A revision and proper accreditation (regardless of alumni standing) of the contributions of Black artists who built your stages.

Please contact us to provide you with the names and contact information of the victims to help you in your investigation.

While we acknowledge our brother Anthony LeBlanc's new role as the first Black executive producer of The Second City, the task he has been charged with is no more than integration into a burning house.While you use him to sort out a mess decades in the making, we will also guide you in moving forward. We demand the following:

- Hiring of an outside, independent HR firm.

- Hiring of an outside BIPOC-owned Diversity \& Inclusion firm.

- Hiring of a BIPOC Executive producer by a steering committee with representatives of the BIPOC LQBTIA+ community from the current student body.

As Black alumni and current employees, we feel it is our responsibility to try to keep our brothers and sisters safe. You use our names to market your business, however we cannot in good conscience recommend The Second City as an effective place for Black comedy to thrive. We understand you may need time to implement these changes. We look forward to hearing from you within 72 hours.

Signed,

Aasia LaShay Bullock
Ali Barthwell
Amber Ruffin
Ashley Nicole Black
Chris Redd
Christina Anthony

Aasia LaShay Bullock

Ashley Nicole Black

Chris Redd

\author{
Colette Gregory \\ David Pompeii \\ Dewayne Perkins \\ Diona Reasonover \\ Dwayne Colbert \\ Edgar Blackmon \\ Lisa Beasley
}

\author{
Pip Lilly \\ Rashawn Nadine Scott \\ Sam Richardson \\ Shantira Jackson \\ Tawny Newsome \\ Tyler Davis \\ (Bullock et. al)
}

Similar letters directed at Second City were made public by Latinx, LGBTQIA, and APIMEDA (Asian, Pacific Islander, Middle Eastern, and Desi American) improvisers. This exchange, as well as the steps planned and taken to "make Second City a purposefully anti-racist institution" (from Second City's reply to the letters), are documented on the Second City website under the 11 June 2020 "Updates from the Second City.” This small archive is worth a read. In August 2020, the New York Times published an article by Melena Ryzik and Jack Malooley titled “Second City Is Trying Not to Be Racist. Will It Work This Time?" The article 
is a significant follow-up on this project and provides an extensive and detailed report on this dynamic as it plays out.

In the same week the open letter to Second City was published, Olivia Jackson started a petition against iO on change.org. It too contained several demands, among them the decentralization of "theater decision making," "more power to BIPOC," and a public acknowledgment and apology from owner Charna Halpern for the "institutional racism perpetuated at iO as well as her individual history of racism." Other demands included the hiring of an "outside BIPOC Diversity \& Inclusion Coordinator," and the commitment to "a fully revised and decolonized curriculum in order to create a learning environment where Black students can thrive." Halpern responded immediately in a letter posted on Change.org. Echoing Alexander's letter several days prior, she apologized in emotional and personal terms:

\footnotetext{
My heart is being pulled and broken in so many different directions right now. I have been outraged at the police brutality and the violence against the Black Lives Matter movement. My heart breaks again to see and hear the experiences of BIPOC performers that have been uncomfortable, discriminated against, pained, and felt unheard at iO. As the owner of iO I must take responsibility for the failings in every department, and for my own failings. I am sorry.

I started iO 40 years ago to legitimize improv as an art form and to create a safe space for all artists to be creative. I realize now that despite my goal to foster an environment of support and positive embrace, I have not been engaged or active enough in supporting the BIPOC and LGBTQIA+ members of our community. The world has changed greatly in my time and only I am responsible for my lack of adapting with these changes.

I am sorry for ever patting myself on the back for incremental change. I am sorry for ever thinking small reforms were enough to fix systemic and institutional problems in our culture. (Response)
}

Combined with Alexander's letter, Halpern's reply provides enough material to analyze the novel genre of forced white institutional apology blended with the emotional reassurance of one's good intentions, reminding everyone of the great work they have done in the past on behalf of the community in general. Despite her lengthy apology, the iO will not go down the same road of betterment taken by Second City. As Halpern hinted in her response letter ("The future of iO is fragile. Our forced closure caused by Covid-19 has taken a large financial toll on the business"), the theater has fallen victim to the loss of revenue caused by COVID-19. Halpern states she was unable to pay property taxes during the shutdown and is closing iO permanently. Quoted in an article from the Chicago Tribune, she maintains that "If it were not for the pandemic I would not be closing. I would be meeting with the protesters" (George). 
What does all of this mean for the present study? Is it extremely timely or entirely out of date? In some ways, both are true. While what I have written up as a "sketchy report of Chicago improv" may have been eclipsed by reality, the broader lines of analysis are less likely to be overtaken by day-to-day political developments of and in institutionalized improv comedy. Ryzik and Malloley's New York Times article publicizes numerous examples of anti-Blackness in improv, and since white denial no longer holds up the way it did when I began the project, such accounts speak to the urgency of a deeper analysis of improv's persistent anti-Black structures. This is not to suggest that recent developments can fundamentally disband the discursive episteme and libidinal economy of white subjectivity that shapes improv poetics, practice, and institutionality at its core. Even though the response letter from the current management of Second City demonstrates a willingness to "tear it all down" ("Updates"), I am unsure what that might mean or entail. This does not concern the individuals or their intentions but the discursive capacity for the fundamental change necessary to reframe improv and its axioms in order to erode the very Humanity on which improv relies as the praxis of intuitive humorous play. Improv would need to become something fundamentally different. In fact, the way in which improv crystallizes profoundly Humanist axioms and practices makes it a rich sphere for future analysis.

What is so special about this performative mode that it deserves particular scrutiny in this way? Aside from the fact that it was a short personal step for me as a scholar in the Humanities and as a professional improviser, I have given the most obvious answers above: in its reinvigoration of Humanist vitalism through the elements of intuition, play, and humor, and given its position within popular culture, improv presents itself as a discursive nexus for the anti-Black modern popular. Fetishizing notions of freedom, equality, and the transcendence of the rational self, improv draws on a traditional Humanism that was going out of fashion by the mid-twentieth century. This vitalist reinvigoration of the modern Human subject makes improv an apt field for investigating this specific work. Moreover, drawing on the mode of improvisation traditionally associated with Black cultural production, improv's whiteness creates a visible disparity up for discussion: "Why is improv so white, when improvisation is known discursively as Black cultural expression?" is a question everyone can understand. However, as it turns out, improv in this project serves at times as a vehicle to discuss modern anti-Blackness and anti-Black abjection as a white self-making principle irrespective of the stage craft itself. Improv becomes a sphere of magnified white modern self-making. 


\subsection{Retrospective reflections on scholarship in whiteface}

+++ TRIGGER WARNING+++ In this final section, I reflect on the performativity of my scholarship. In this study I set out to maintain a constant alertness and critical self-reflection of the ways I am implicated in the issues I address. At the same time, I thought it best not be ever-present in the writing, so as to develop the argument itself and avoid self-centered navel-gazing. While in some sections I might have found a good balance, in others I may have tended to one side or the other. So in the final section of this study, I consider this project's performativity. Even though I seek to keep this reflection on the structural plane, readers who despise such white self-reflections may be irritated. +++TRIGGER WARNING+++

What does this project contribute? What epistemic gain does it offer? It provides a counterpoise to the recently industrious but still largely celebratory academic production on all things improv. Methodologically, it offers a meticulous yet flexible way of engaging with theory to meet the specific demands of a chosen object of study, and it exemplifies the potential of exploring the interdisciplinary space between cultural studies, critical race theory, psychoanalysis, and neuroscience. More specifically, reading Adorno's critique of jazz and US popular culture through an Afro-pessimist framework improves our understanding of the debate about his theories and positions. Yet it feels inaccurate to read this as my contribution because the principal labor in this regard was done by scholars like Saidiya Hartman and Frank Wilderson. More broadly, when it comes to the real issues discussed in this dissertation, attempting to pin down my contribution from the position of white authorship is pointing at a mirage. In this performative constellation of author, content, and audiences, the notion of contribution is superficial, toothless, and even complicit in veiling the fact that I as author-subject remain implicated in the problems I discuss. To me, the term "contribution" implies a sense of ownership, which falls in line with Locke's labor theory of property; he posits that if one labors on something given, that is, on apparently "unowned" resources, one can claim ownership of the product. To my mind, this idea of ownership links the who with the what the academic world knows as "contribution." But the knowledges I have mobilized and the anecdotes of my interview partners are not unowned resources, and my scholarly labor in analyzing them does not make them mine. And even if that were not the case, in view of the Afro-pessimist framework that has guided me, I couldn't even fantasize what there is to contribute to, because the concept of contribution also involves the chimera of development, advancement, and some sort of telos.

In the introduction, I consider Sara Ahmed's "Declarations of Whiteness: The Non-performativity of Antiracism” and Christina Sharpe's statement that 
"the only people who can be Afropessimists are non-Black people" (par. 81). How does this project relate to Sharpe's declaration? What is its performative effect? What does it do? On a superficial level, my analysis erodes the violently Humanist axioms and libidinally driven assumptions that have structured improv practice and its theoretical ground. It does so by scrutinizing central tenets like vitalism, egalitarian play, romanticized intuition, and universalized humor, laying bare the ways in which anti-Black violence is an integral part of improv. In eroding knowledge, challenging naturalized axioms, questioning habitualized lines of reasoning, and contesting Humanist assumptions I draw on a variety of disciplines, authors, and approaches, most centrally on psychoanalytic concepts understood and framed as embodied. To do this work at all, I rely on concepts that radically challenge this modern Humanism. I found those in Afro-pessimism, which facilitates the white autocritique attempted in this project. White autocritique implies the unstated assumption that whiteness can, in fact, be eroded by white people. And yet this optimism of the will is already a luxury that comes with the property of whiteness, to use Harris's term. I use Afro-pessimism to serve my structurally solipsist white-on-white critique. It is weaponized to attack the Humanist episteme and what emerges from it. My project, then, inhabits the problematic it discusses and performs the same solipsist procedure it critiques. It is thus important to note again that I could not have completed this project without the Black scholarship I have cited, and the vast range Black knowledges that I have not cited. There has been no mention of Jared Sexton, Patrice Douglass, David Marriot, Selamawit D. Terrefe, Fred Moten, or the entire body of work done in Black Studies before them. These lacunae in the bibliography are not incidental. I made a conscious decision to work with white scholars like Kristeva, Broeck, Winnicott, and Freud to formulate my own attacks on whiteness and white scholarship, and on improv's whiteness in particular. In retrospect, this decision was founded on two things: a) the unease that came with working primarily with Black scholarship, which I felt to be obliterative, b) the idea that white people should somehow clean up their own backyard first before asking Black scholars for help. I must concede that each one of those defensive justifications is futile. Obliteration will always take place in a configuration like this and drawing on white scholarship in no way prevents it - quite the contrary. Further, the idea of cleaning up Humanism's backyard is bound to the hopeful fantasy that the erosion of white knowledges is a) possible and b) leads to something better. These are mistakes I have made. A different kind of citational practice is called-for.

However, so as not to linger on moral judgement calls, let me consider the structural repercussions of white scholar-subjects deploying Afro-pessimism to attack white Humanism. In the introduction I laid out how this project was in- 
stigated by an observable Black absence from improv. It then became clear to me that the object under scrutiny was not so much Blackness as it was whiteness. Whiteness took the stage where Black absence was previously present. This recentering of whiteness did not feel good, but I saw no alternative that would not make me an ethnographer or explorer of Blackness. Thus I weaponized Afro-pessimism as a conceptual ground for the labor of attempting to mark whiteness by discussing the historical, discursive, and libidinal reasons for its structural unmarked-ness. But did present whiteness turn out to be an in any way more definable or distinct object of study than absent Blackness? What remains from it after an analysis like this one? One crucial privilege that comes with whiteness is that it does not need to position itself. The flipside is that, even though I personally speak about being positioned as white, philosophically speaking, whiteness as such is not a position. It is ubiquitous. Even though individual and collective, discursive and affective anti-Black abjection brings about white positionality, being white is not a position. This echoes Harris's notion of whiteness as property, as entitlement as such: whiteness is the property regime. Afro-pessimism, as much as it cannot position itself, also cannot position whiteness - at least as far as I can see. So while the attacks on white Humanist concepts, assumptions, and practices constitute the practical and visible labor of this project, the emotional agony and libidinal challenges that accompany it reveal that the white scholar faces an underlying (Sisyphean) struggle against this white ubiquity. Further, the imagined or actual anti-Humanist destruction of the world as we know it would leave me with nothing, in existentialist terms. I would no longer be a sociable subject. Would I be capable of dealing with that? Does the work of marking whiteness by describing its practices need to be understood as a transumption of the very maintenance of whiteness under attack? Is it inspired and fueled by anti-Black abjection-as-scholarship? Is it at all possible for a white scholar-subject to work toward their own annihilation? Or is this the only act the white subject does not have the capacity to perform?

I have often given up on this project, convinced that as a white man I must not (and cannot) write such a piece or engage with anti-Blackness at all. I pondered cop-outs, like writing everything under erasure, handing in 300 empty pages, or giving up entirely. Recognizing the self-indulgence or privilege in these outs, I understood that I could not disappear behind the problem or its discussion. At some point I realized that these solutions would only solve my specifically white issue, problem, and unease with Black absence from improv. They offered a way for me to imagine my work as morally unimpeachable, and so meant dodging, taking myself out of the equation, performing the white transcendence of an otherwise unresolvable issue. But as a white subject, a white improvisor, a white scholar, I embody everything I critique. I continue to be impli- 
cated on all levels. The affective sensation of having understood something, the intellectual satisfaction of having connected dots in a meaningful way, the sense of closed logic when A can be explained by relating B, C, and D, the feelings of relief when a project like this is wrapped up: these affects are libidinally grounded in the Humanist imaginations of coherence, closure, and relational connection. But the issues I have discussed are not resolvable within Humanist imaginings or language. There can be no intellectual conclusion, no emotional closure, no moral absolution that scholarship or any other kind of work can offer in this regard. Afro-pessimism does not offer an ending or suggest ways to get there. Quite the contrary, Afro-pessimism posits irreconciliation in that argumentational space. Can I do that too? Because: this is not an end. Taking and using the notion of a "non-ending" in this way becomes the final Afro-pessimist weapon available to the white scholar. Here, "wallowing in contradictions" (Wilderson), I profit most from white voluntarism. As a white subject, I have the capacity to take this idea for my own ends without repercussions. And indeed, because I cannot undo anti-Blackness or suggest ways to dismantle it, I make use of that option. In view of methodological and axiomatic consistency and the violent obliteration it entails, to claim that this is not an end is cogent at this point in the argument. At the point where it just does not go any further. 